\title{
Efficient ionic liquid-based platform for multi-enzymatic conversion of carbon dioxide to methanol
}

Zhang, Zhibo; Muschiol, Jan; Huang, Yuhong; Sigurdardóttir, Sigyn Björk; von Solms, Nicolas; Daugaard, Anders E.; Wei, Jiang; Luo, Jianquan; Xu, Bao-Hua; Zhang, Suojiang

Total number of authors:

11

Published in:

Green Chemistry

Link to article, DOI:

$10.1039 / \mathrm{c} 8 \mathrm{gc0} 2230 \mathrm{e}$

Publication date:

2018

Document Version

Peer reviewed version

Link back to DTU Orbit

Citation (APA):

Zhang, Z., Muschiol, J., Huang, Y., Sigurdardóttir, S. B., von Solms, N., Daugaard, A. E., Wei, J., Luo, J., Xu, BH., Zhang, S., \& Pinelo, M. (2018). Efficient ionic liquid-based platform for multi-enzymatic conversion of carbon dioxide to methanol. Green Chemistry, 20(18), 4339-4348. https://doi.org/10.1039/c8gc02230e

\section{General rights}

Copyright and moral rights for the publications made accessible in the public portal are retained by the authors and/or other copyright owners and it is a condition of accessing publications that users recognise and abide by the legal requirements associated with these rights.

- Users may download and print one copy of any publication from the public portal for the purpose of private study or research.

- You may not further distribute the material or use it for any profit-making activity or commercial gain

- You may freely distribute the URL identifying the publication in the public portal 


\section{Efficient Ionic Liquid-based platform for Multi-Enzymatic} Conversion of Carbon Dioxide to Methanol

Zhibo Zhang, a,b Jan Muschiol, a Yuhong Huang,a Sigyn Björk Sigurdardóttir,a

Bao-Hua Xu, b Suojiang Zhang *b and Manuel Pinelo*a

Low yields commonly obtained during enzymatic conversion of $\mathrm{CO}_{2}$ to methanol are attributed to low $\mathrm{CO}_{2}$ solubility in water. In this study, four selected ionic liquids with high $\mathrm{CO}_{2}$ solubility were separately added to the muti-enzyme reaction mixture and the yields compared to pure aqueous system (control). In an aqueous $20 \%$ [CH][Glu] system, yield increased app. 3.5-fold compared to the control (app. 5-fold if NADH regeneration was incorporated). Molecular dynamics simulation revealed that $\mathrm{CO}_{2}$ remains for longer in a productive conformation in the enzyme in the presence of $[\mathrm{CH}][\mathrm{Glu}]$, which explains the marked increase of yield that was also confirmed by isothermal titration calorimetry - lower energy $(\Delta \mathrm{G})$ binding of $\mathrm{CO}_{2}$ to FDH-. The results suggest that the accessibility of $\mathrm{CO}_{2}$ to the enzyme active site depends on the absence/presence and nature of the ionic liquid, and that the enzyme conformation determines $\mathrm{CO}_{2}$ retention and hence final conversion.

aDepartment of Chemical and Biochemical Engineering, Building 229, Technical University of Denmark, DK-2800 Kgs. Lyngby, Denmark. E-mail: mp@kt.dtu.dk bBeijing Key Laboratory of Ionic Liquids Clean Process, Key Laboratory of Green Process and Engineering, State Key Laboratory of Multiphase Complex Systems, Institute of Process Engineering, Chinese Academy of Sciences, Beijing 100190, P. R. China. E-mail: sjzhang@ipe.ac.cn

cState Key Laboratory of Biochemical Engineering, Institute of Process Engineering, Chinese Academy of Sciences, Beijing 100190, PR China

\section{Introduction}

One of the greatest environmental challenges we face today are the large emissions of carbon dioxide $\left(\mathrm{CO}_{2}\right)$ into the atmosphere each year, which contribute to global warming, ocean acidification, melting of icebergs and the energy crisis. ${ }^{1,2}$ Ideally, $\mathrm{CO}_{2}$ ought to be converted to useful chemical and fuels (e.g. methanol) for renewable energy utilization and simultaneously alleviation of the problem of $\mathrm{CO}_{2}$ emissions. Therefore extensive efforts have been made to bring about catalytic hydrogenation of $\mathrm{CO}_{2}$ via chemistry, electrochemistry, photochemistry and enzymatic conversions. ${ }^{3,4,5,6}$ Due to the inherent thermodynamic stability and low reactivity of $\mathrm{CO}_{2}$, production of methanol by enzymatic conversion has significant advantages over conventional techniques owing to the high selectivity, high efficiency, mild experimental conditions, and environmental friendliness of enzymatic catalysis. $^{6}$

Inspired by the biological metabolic pathway, sequential reduction of $\mathrm{CO}_{2}$ to formic acid, formaldehyde and methanol can be achieved by using formate dehydrogenase (FDH), formaldehyde dehydrogenase (FaldDH), and alcohol dehydrogenase (ADH), respectively. ${ }^{6,7,8}$ However, the yield of methanol achieved in this type of system is only $43.8 \% .^{7}$ The low conversion was partly explained by the fact that the reaction rate of the first reaction in the 
Indeed, Rusching et al. reported that formic acid oxidation was 30 times faster than $\mathrm{CO}_{2}$ reduction catalyzed by FDH. ${ }^{9}$ Thus the $\mathrm{CO}_{2} \rightarrow$ formic acid step is likely to be a bottleneck in the reduction of $\mathrm{CO}_{2}$ to methanol. In this regard, we envisioned that a higher yield of product, either formaldehyde or methanol, could be reached by increasing the concentration of substrate $\left(\mathrm{CO}_{2}\right)$ in the solution, which may drive the transformation of $\mathrm{CO}_{2}$ to formic acid forward. In addition, it could also be helpful to further promote the reaction rate by incorporating a membrane to the system so that products would be immediately separated from reaction and thus switch the equilibrium towards the formic acid.

Ionic liquids (ILs) have great capacity to capture $\mathrm{CO}_{2}$ via electrostatic forces, van der Waals forces, hydrogen bonds and other physical effects. ${ }^{10}$ Amine functionalized cation-tethered ILs have been used for $\mathrm{CO}_{2}$ capture, in which $0.5 \mathrm{~mol} \mathrm{CO}_{2}$ per mol of IL could be absorbed through a carbamate mechanism. ${ }^{11}$ Amino acid ILs could capture almost $1 \mathrm{~mol} \mathrm{CO}_{2}$ per mol of IL by forming carbamic acid rather than carbamate. ${ }^{12}$ Furthermore, the high potential of $\mathrm{CO}_{2}$ electronic reduction could be lowered by ILs to achieve a lower energy barrier. ${ }^{13,14}$ To date, ILs have been used in various enzymatic reactions, e.g. with cellulases and ADH. ${ }^{15}, 16,17,18$ Recently, several biocompatible and environmentally friendly ILs have been identified which are composed of naturally-derived materials such as sugars, amino acids, and choline. ${ }^{19}$ Several proteins have been successfully dissolved in choline dihydrogenphosphate $[\mathrm{CH}][\mathrm{DHP}]$ without denaturation. ${ }^{20} 70 \%$ of the initial redox activity of Cytochrome C remained more than one year after dissolving in a mixture of $[\mathrm{CH}][\mathrm{DHP}]$ and water. ${ }^{21}$ Amino acid-based ILs as benign media have been also reported in biomedical applications. ${ }^{22,}{ }^{23}$ ILs could thus be promising substitutes of traditional buffers for conducting selected enzymatic reactions.

For in-situ removal of products (methanol and $\mathrm{NAD}^{+}$) and recycling of enzymes, a separation system platform is additionally required. Recently, inspired by membrane fouling mechanisms, we proposed a simple approach to immobilize enzymes in membranes using "reverse filtration" of the enzyme solution. ${ }^{8}$ In this system, enzyme immobilization was achieved by hydrogen bonding, entrapment and hydrophobic or electrostatic adsorption, ${ }^{24}$ The activity of the immobilized enzymes could be maintained to approximately that of the free enzymes due to the mild and fast immobilization procedure. High enzyme loading could also be maintained and the contact time substrate-enzyme could be controlled by changing pressure. However, to produce one mole of methanol in such a cascade reaction, three moles of reduced nicotinamide adenine dinucleotide (NADH) are stoichiometrically consumed, as the cofactor (NADH) acts as a hydrogen and electron donor at each step of the reduction reaction. ${ }^{25}$ Converting the oxidized form of the cofactor $\left(\mathrm{NAD}^{+}\right)$to $\mathrm{NADH}$ is essential for reducing cost and enhancing methanol production. Normally, NADH regeneration is accomplished by chemical, photochemical, and electrochemical methods, but such regeneration can be also attained by adding another enzyme system which requires NAD+ to proceed (Scheme 1). ${ }^{26}$

In this study, biocompatible ILs composed of choline and amino acids (i.e. [CH][Glu], [CH][Pro], [CH][Gly], and[CH][His]) were designed and synthesized in order to increase $\mathrm{CO}_{2}$ solubility and stabilize FDH. These ILs were incorporated in a membrane reactor system which enabled in situ removal of products from the reaction, as illustrated in Figure 1. Four kinds of ILs as co-solvent were evaluated in the biocatalytic membrane reactor by passing a mixture of $\mathrm{CO}_{2}$, IL and cofactor through the enzyme-loaded membrane. To our knowledge, this is the first report of multi-enzymatic conversion of $\mathrm{CO}_{2}$ to methanol in ILs with NADH regeneration. This integration of ILs and biocatalytic membrane provides a promising avenue for a practical $\mathrm{CO}_{2}$-based sustainable chemistry.

\section{Results and Discussion}




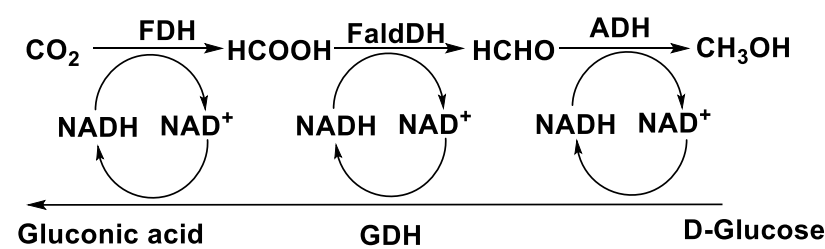

Scheme 1. Multi-enzyme system for methanol synthesis from $\mathrm{CO}_{2}$ with in situ regeneration of NADH.

Fabrication of biocatalytic membrane. The immobilization was performed in a membrane assembled in a socalled sandwich mode (polypropylene layer - skin layer - polypropylene support) so that the membrane support layer was positioned to face the feed, while underneath the skin layer an extra polypropylene support was placed to act as a cushion to alleviate membrane compression and peeling of the skin layer (Figure 1). Based on the "fouling-induced immobilization" method, the three enzymes (i.e. FDH, FaldDH and ADH) were simultaneously immobilized in the membrane. During enzyme loading in the membrane, the permeate volume over time was collected, as presented in Figure S1. The mechanism of membrane fouling induced by the enzyme solution filtration was categorized into four fouling models which are presented in Table S1 and identified as standard, intermediate, complete blocking, and cake layer models. ${ }^{27,}{ }^{28}$ The cake layer model, showing a high value correlation coefficient, was found to best describe the loading mechanism. In the initial stage of the filtration process, only the cake layer model fitted the experimental data, which indicated that most enzymes are deposited on the skin layer of the membrane. As filtration time increased, the experimental data also correlated well with other models because the fouling layer created by the enzymes acts as an additional membrane. ${ }^{8}$ The morphology of the enzyme-immobilized membrane was characterized by SEM, and is shown in Figure 2. The figure shows the skin layer, which is made up of regenerated cellulose (Figure 2a), and some enzyme aggregates adsorbed on the surface of the polypropylene support fibres (Figure 2b,c). From the mathematical modelling and characterization by SEM, the fouling-induced enzyme immobilization was found to involve at least two mechanisms: entrapment and adsorption. In Figure 2c it can be seen that some enzymes were bound to the support fibres by hydrophobic adsorption. Based on mass balance calculations by Bradford assay, $2.66 \mathrm{mg}$ of protein was immobilized in the membrane, which corresponds to enzyme loading efficiency of $76 \%$. Accordingly, the permeability dropped to $3.04 \mathrm{~L} \mathrm{~m}^{-2} \mathrm{~h}^{-1}$ bar $^{-1}$ after enzyme loading, which is around 10 times lower than that of virgin membrane $(330 \pm 6 \mathrm{~L}$ $\left.\mathrm{m}^{-2} \mathrm{~h}^{-1} \mathrm{bar}^{-1}\right)$.

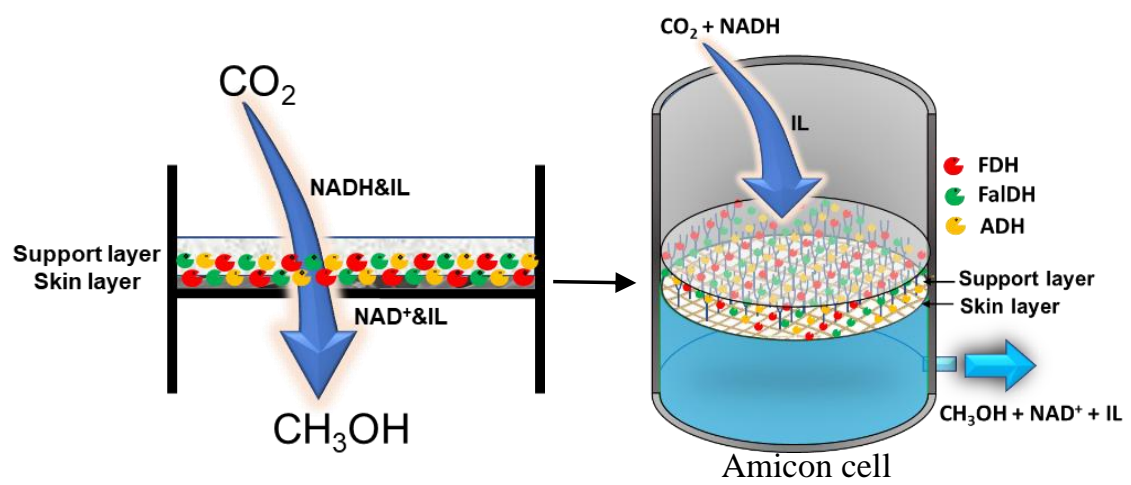

Figure 1. The immobilization strategy of enzymes in membrane for multi-enzymatic cascade reaction.

The synthesis of methanol from $\mathrm{CO}_{2}$ catalyzed by the three-enzyme cascade reaction in Tris- $\mathrm{HCl}$ buffer was performed with the membrane loaded with enzymes. According to the reaction route, three moles of NADH are stoichiometrically consumed to produce one mole of methanol in the cascade reaction. Therefore the methanol 


$$
Y_{\text {methanol }}(\%)=\frac{C_{\text {methanol }} * 3}{C_{N A D H, \text { initial }}} * 100
$$

116 Where $C_{\text {methanol }}$ is the methanol concentration $(\mathrm{mM})$, and $C_{N A D H \text {,initial }}$ is the initial NADH concentration (mM).

117 After 30 min reaction, a methanol yield of $24.5 \%$ was obtained for the immobilized system, whilst practically the same yield (23.5\%) was obtained for an equivalent free enzyme system (using the same amount of enzymes in free form) (Figure 3a). The similar yield obtained confirmed that no enzyme activity was sacrificed during immobilization. The low yield of methanol obtained was explained by the kinetics of the reaction, as reported by Luo et al. ${ }^{8}$ As explained above, the reaction rate of the forward reaction $\left(\mathrm{CO}_{2} \rightarrow\right.$ formic acid) is much lower than that of the reverse reaction (formic acid $\rightarrow \mathrm{CO}_{2}$ ). For the second enzyme, FaldDH, the reaction (formic acid $\rightarrow$ formaldehyde) was also found to be less efficient than the reverse reaction (formaldehyde $\rightarrow$ formic acid). However, for the third enzyme, $\mathrm{ADH}$, the forward reaction (formaldehyde $\rightarrow$ methanol) was much more efficient than the reverse reaction (methanol $\rightarrow$ formaldehyde). ${ }^{8}$ Additionally, Luo et al. suggested that in order to be activated, the second reaction required a threshold concentration of formic acid. Therefore the first reaction from $\mathrm{CO}_{2}$ to formic acid probably plays a decisive role in this cascade reaction.

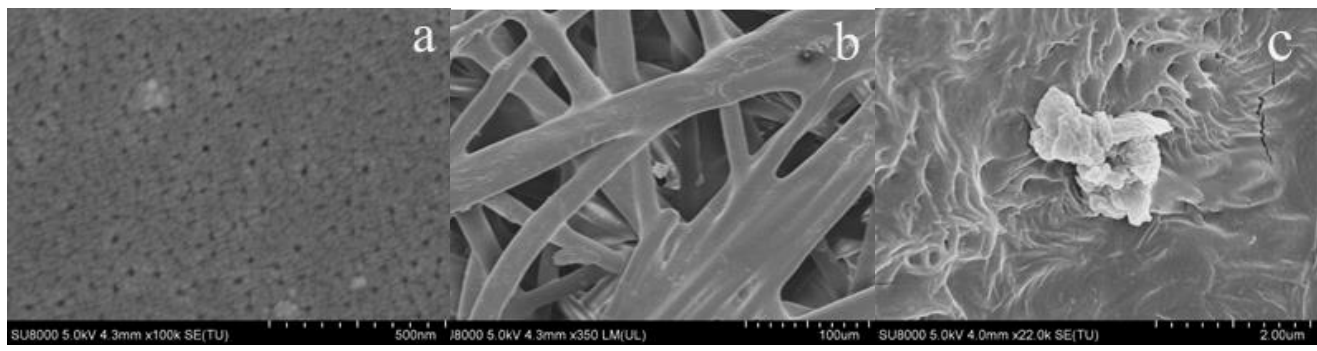

Figure 2. (a) SEM images of (a) skin layer (regenerated cellulose)Overview of skin layer (regenerated cellulose); (b) support layer (polypropylene nonwoven fibers); (c) View of support layer after enzyme immobilization.

Muti-enzymatic reaction in the ILs with co-immobilization of enzymes. The four selected ILs have a high capacity to absorb $\mathrm{CO}_{2}$, where one mole of IL can chemically absorb half a mole of $\mathrm{CO}_{2} \cdot{ }^{29}$ The adsorption of half a mole of $\mathrm{CO}_{2}$ by each mole of IL was proposed by Han et al, and similar mechanisms of $\mathrm{CO}_{2}$ adsorption by ILs were also reported by other authors. ${ }^{11,29,30}$ Han et al also demonstrated that $[\mathrm{CH}][\mathrm{AA}]$ can be repeatedly recycled for $\mathrm{CO}_{2}$ adsorption, owing to $\mathrm{CO}_{2}$ can be desorbed from IL by bubbling $\mathrm{N}_{2}$. Therefore, the process of $\mathrm{CO}_{2}$ adsorption is reversible, and ILs can provide FDH with a proper $\mathrm{CO}_{2}$ concentration with a slow-releasing system, as required by FDH. As illustrated in Figure 3a (red points), the measured molar ratio of $\mathrm{CO}_{2}$ to the ILs could slightly exceed 0.5 . The slightly excess of $\mathrm{CO}_{2}$ :IL molar ratio suggests that physical adsorption could also contribute to the uptake of $\mathrm{CO}_{2}$. Based on the $\mathrm{CO}_{2}$ solubility in the pure ILs, the $\mathrm{CO}_{2}$ concentration in the four kinds of $20 \%$ ILs was calculated to be in the range from 467 to $714 \mathrm{mM}$, which is far higher than the $\mathrm{CO}_{2}$ solubility in water $(33 \mathrm{mM}) .{ }^{31}$ Furthermore, the $\mathrm{CO}_{2}$ adsorption rate in an aqueous IL solution is faster than in the pure IL. Indeed, $\mathrm{CO}_{2}$ adsorption equilibrium is reached after 20 minutes in aqueous $5 \mathrm{wt} \%$ [CH][AA], whilst the saturation of $\mathrm{CO}_{2}$ in pure $[\mathrm{CH}][\mathrm{AA}]$ will take at least 4 h. ${ }^{29,}{ }^{32}$ Therefore aqueous ILs can be as such an ideal medium for enzymatic reactions. 

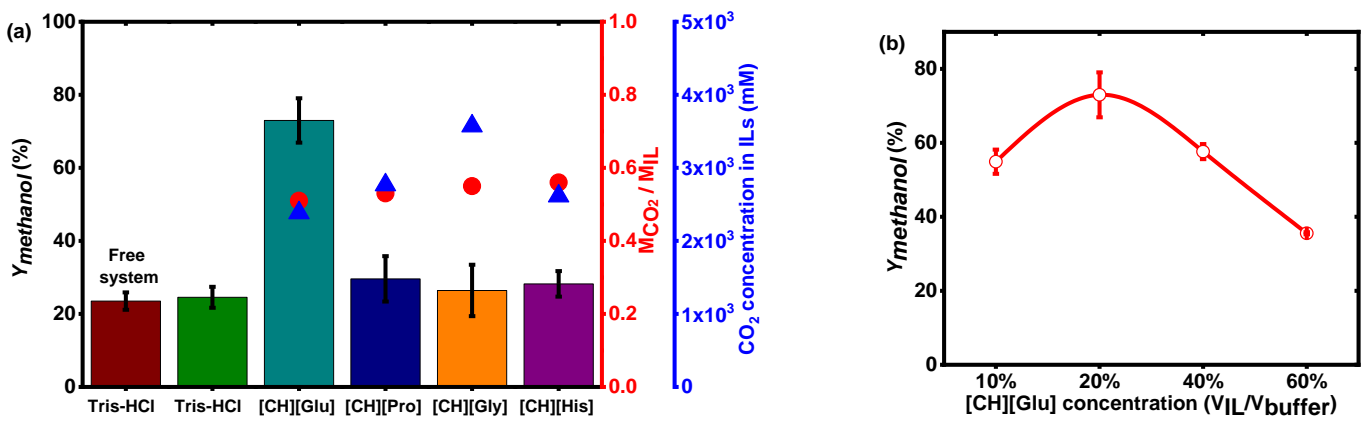

Figure 3. (a) Yield of methanol in Tris- $\mathrm{HCl}(\mathrm{pH}=7.0)$ and in four kinds of $20 \%$ ILs (left); solubility of $\mathrm{CO}_{2}$ in the absolute ILs with molar ratio of $\mathrm{CO}_{2}$ to the IL $\left(\mathrm{M}_{\mathrm{CO} 2} / \mathrm{M}_{\mathrm{IL}}\right)$ (left, red circle); $\mathrm{CO}_{2}$ concentration in ILs (left, blue triangle). All the enzymatic reactions were conducted in the membrane except "Free system". (b) Methanol production at different concentrations of $[\mathrm{CH}][\mathrm{Glu}]$. An enzymatic membrane reactor equipped with a $10 \mathrm{kDa}$ regenerated cellulose membrane (skin layer facing feed) was used. Recycling of immobilized enzymes was conducted using fresh NADH solution in Tris-HCl buffer and containing $20 \%[\mathrm{CH}][\mathrm{Glu}]$ buffer $(\mathrm{NADH}=5 \mathrm{mM})$.

$\mathrm{CO}_{2}$ reduction to methanol with the enzyme-loaded membrane (i.e. FDH, FaldDH, and $\mathrm{ADH}$ ) was performed in the presence of $20 \% \mathrm{ILs}\left(\mathrm{V}_{\mathrm{II}} / \mathrm{V}_{\text {buffer }}=20 \%\right)$ (Figure 3a). The maximum methanol yield was achieved using [CH][Glu] and was $\sim 3.5$ times higher than the results of multi-enzymatic reactions in Tris-HCl buffer. The same reaction was similarly examined for the other three ILs, but conversion of $\mathrm{CO}_{2}$ was not significantly improved compared to the reactions in Tris- $\mathrm{HCl}$ buffer. In the past, Liu et al. increased the pressure during operation as an additional strategy to achieve high $\mathrm{CO}_{2}$ concentration in solution. They found that the reaction rate increased from $(1.20 \pm 0.09) \times 10^{-3}$ to $(2.17 \pm 0.07) \times 10^{-3} \mu \mathrm{mol} / \mathrm{min}$ when $\mathrm{CO}_{2}$ pressure was increased from $0.2 \mathrm{MPa}$ to $0.5 \mathrm{MPa}$, but almost no change was detected when pressure was further increased to $1.0 \mathrm{MPa} .{ }^{33}$ The stable yield detected when pressure was increased above $0.5 \mathrm{MPa}$ was attributed to the fact that NADH concentration probably became the limiting factor. In our case, methanol yield could be improved almost three fold by increasing the $\mathrm{CO}_{2}$ concentration 15 times in the $[\mathrm{CH}][\mathrm{Glu}]$ system compared to reactions in Tris- $\mathrm{HCl}$ buffer.

To further improve the efficiency of $\mathrm{CO}_{2}$ conversion, the $[\mathrm{CH}][\mathrm{Glu}]$ concentration was studied over the range $10 \%$ to $60 \%[\mathrm{CH}][\mathrm{Glu}]$. The yield of methanol was clearly increased with increasing $[\mathrm{CH}][\mathrm{Glu}]$ from $10 \%$ to $20 \%$. $\mathrm{CO}_{2}$ captured in the solution was noticeably increased by increasing $[\mathrm{CH}][\mathrm{Glu}]$ concentration, thus shifting the reaction equilibrium towards the production of methanol. However, the yield of methanol declined with further increase of the $[\mathrm{CH}][\mathrm{Glu}]$ concentration from $20 \%$ to $60 \%$. Although more $\mathrm{CO}_{2}$ was captured by increasing the IL concentration, conformational changes of the peptide chains of the enzymes could have contributed to the decrease in the activity. Indeed, increasing organic salts concentration has been reported to affect the electrostatic balance in the proteins, with a direct effect on activity. ${ }^{34}$ Furthermore, stability, crystallisation behaviour and aggregation behaviour of proteins have been reported to change dramatically with increasing concentration of ILs in aqueous media. $^{35,36,37}$ Previous studies have also confirmed the difficulty of homogeneously dissolving the proteins in pure ILs without denaturation. ${ }^{38,} 39$ Therefore water-based solvents with small amounts of salts (water-rich IL mixtures) are believed to be the best media for proteins. ${ }^{34}$ This balance between $\mathrm{CO}_{2}$ solubility and protein denaturation can tentatively explain why $20 \%[\mathrm{CH}][\mathrm{Glu}]$ as co-solvent provided the highest yield.

pH effect on enzyme activity. Liu et al. reported that the optimal $\mathrm{pH}$ for reduction of $\mathrm{CO}_{2}$ to formic acid by FDH was $6.0^{40}$. However, neutral conditions ( $\mathrm{pH}$ 7.0) resulted in the highest formaldehyde production from conversion of formic acid to formaldehyde catalysed by FaldDH. ADH, the third enzyme in the sequence, was reported to have an optimal activity at $\mathrm{pH} 8.1$ by Shrabon. ${ }^{41}$ In our case, the optimum $\mathrm{pH}$ value when the reaction took place in buffer (without ionic liquids) was 6.5, which is similar to the optimum pH of FDH (Figure 4a); this result may suggest that the first reaction $\left(\mathrm{CO}_{2} \rightarrow\right.$ Formic acid) plays a decisive role in the performance of the whole reaction. 

or above 7.5, which suggests reduced enzyme activity under both acid and alkali conditions. Previous studies suggested that the activity and structure of the enzymes might be affected by strongly acidic or alkaline media. ${ }^{42}$ Our results showed that the $\mathrm{pH}$ of the $20 \%[\mathrm{CH}][\mathrm{Glu}]$ mixture ( $\mathrm{pH}$ 6.85) was lower than the $\mathrm{pH}$ of the other ILs screened, which could also have influenced the higher conversion of the former compared to the ILs evaluated. Unfortunately, these ILs were synthesized by acid-base neutralization of choline and amino acids. Therefore lowering the $\mathrm{pH}$ of the other ILs was not be possible because to do so would have resulted in decomposition and amino acid precipitation from the solution; thus no direct comparison among the four ILs at the same $\mathrm{pH}$ could be performed.
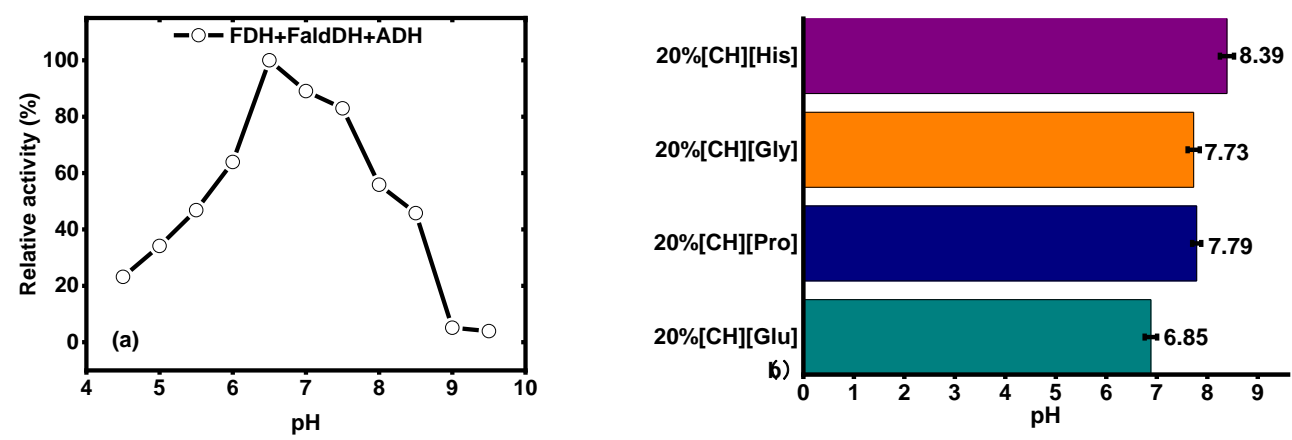

Figure 4. (a) Activity of the three enzymes at different $\mathrm{pH}$ from 4.5 to 9.5 ; (b) $\mathrm{pH}$ values in different kinds of $20 \%$ ILs $\left(\mathrm{V}_{\mathrm{IL}} / \mathrm{V}_{\text {Buffer }}\right)$ after $30 \mathrm{~min}$ bubbling with $\mathrm{CO}_{2}$.

Recycle of the biocatalytic membrane. To evaluate the recyclability of the biocatalytic membrane, FDH, FaldDH and $\mathrm{ADH}$ were co-immobilized in the $10 \mathrm{kDa}$ regenerated cellulose membrane and fresh substrate was fed to the reactor after each of the six 30-minutes reaction cycles. The yield of methanol in the Tris-HCl buffer was maintained at 20\% - 40\% for six runs (Figure 5), which confirmed that enzyme leakage was low and that enzyme activity was not lost during immobilization. In the presence of $[\mathrm{CH}][\mathrm{Glu}]$, the yield of methanol increased and was between $60 \%$ to $75 \%$ during the six runs. A slight decrease in the yield (albeit not significant) was observed after the second run, but no further decrease was observed during the remaining four runs

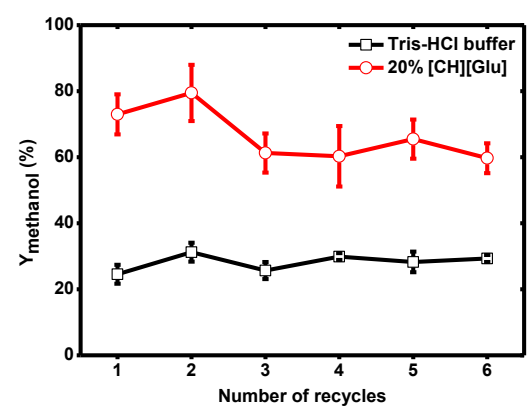

Figure 5. Stability of biocatalytic membrane in Tris- $\mathrm{HCl}$ buffer and $20 \%[\mathrm{CH}][\mathrm{Glu}]$.

Cofactor (NADH) regeneration with glucose dehydrogenase. NADH acts as a terminal electron donor and hydrogen donor in the cascade enzymatic reaction and is consumed stoichiometrically at each step. As a result, three molar equivalents of NADH are consumed to transform one molar equivalent of $\mathrm{CO}_{2}$ in methanol. Efficient regeneration of NADH is crucial for such a cascade enzymatic reaction since the cost of NADH is very high and in-situ generated NAD+ will in turn inhibit the reduction of $\mathrm{CO}_{2}$ and promote the reverse oxidative reaction. In the current study, glucose dehydrogenase (GDH) was used for NADH regeneration and the enzymatic reaction was 

(FDH, FaldDH, ADH) in the $10 \mathrm{kDa}$ regenerated cellulose membrane. D-glucose $(50 \mathrm{mM})$ as the GDH substrate was mixed with NADH solution $(4 \mathrm{~mL})$ containing $20 \%[\mathrm{CH}][\mathrm{Glu}]$, which was pre-bubbled with $\mathrm{CO}_{2}$ for 30 minutes. As seen in Figure 6, the yield of methanol increased from $73 \%$ to $102 \%$ after 30 to 120 min reaction and then reached equilibrium after $120 \mathrm{~min}$. The result indicates that NADH was efficiently regenerated with high activity of GDH. A number of researchers have also reported that the yield of methanol increased with increasing NADH concentration. ${ }^{43,44,45,46}$ Total turnover number (TTN) of up to 10000 has been obtained by using GDH for the regeneration of $\mathrm{NAD}^{+}$, as reported by Obon. ${ }^{47}$ The reduction rate from $\mathrm{NAD}^{+}$to NADH catalysed by GDH is faster than the oxidation of $\mathrm{NADH}$ to $\mathrm{NAD}^{+}$by $\mathrm{ADH}$, as reported by Fauziah et al. ${ }^{26}$ The reaction rate for the reaction from $\mathrm{NAD}^{+}$to $\mathrm{NADH}$ catalysed by $\mathrm{GDH}$ was $6.3 \mu \mathrm{mol} / \mathrm{mg} \cdot \mathrm{min}$, while the reaction rate for the reaction from $\mathrm{NADH}$ to $\mathrm{NAD}^{+}$catalysed by $\mathrm{ADH}$ was $4.7 \mu \mathrm{mol} / \mathrm{mg} \cdot \min$. Furthermore, converting NADH to $\mathrm{NAD}^{+}$ catalysed by $\mathrm{ADH}$ was much more efficient than with the other two enzymes (FDH and FaldDH). ${ }^{8}$ The reaction rate for the cascade reaction is limited by the slowest reaction. Therefore the reaction rate for converting $\mathrm{NAD}^{+}$to NADH is far higher than the oxidation of NADH by the three enzymes. Lastly, after two hours there was no further improvement in yield of methanol. Probably, due to product inhibition by high methanol concentration in the solution, the reversible enzymatic reaction would progress any further.

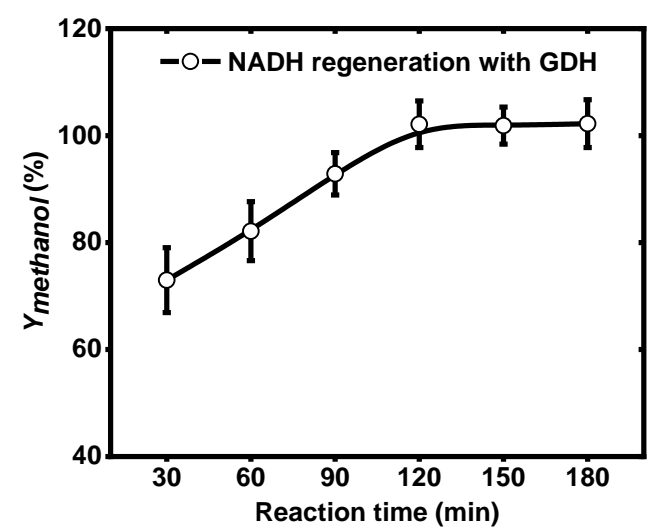

Figure 6. Methanol production as a function of reaction time with coupled GDH for cofactor regeneration

Molecular Simulation. Molecular dynamics simulations on FDH with different solvents (i.e. water, $20 \%[\mathrm{CH}][\mathrm{Gly}], 20 \%[\mathrm{CH}][\mathrm{Glu}], 20 \%[\mathrm{CH}][\mathrm{His}]$ and $20 \%[\mathrm{CH}][\mathrm{Pro}])$ were performed in order to evaluate the effect of the aqueous IL on the enzyme. As depicted in Figure 7a, all simulations using aqueous ILs showed a similar trend with respect to the root mean square deviation (RMSD) value of the $\mathrm{C} \alpha$ backbone over the MD simulation time, with the exception of $20 \%[\mathrm{CH}][\mathrm{Glu}]$ which approached a lower maximum value. The average RMSD values for the simulation in water and using the aqueous ILs (except $[\mathrm{CH}][\mathrm{Glu}]$ ) ranged from 1.7 to $1.9 \AA$ (Figure S2). In contrast, the average RMSD values for the $20 \%[\mathrm{CH}][\mathrm{Glu}]$ simulation of $1.3 \AA$ were markedly lower compared to the other solvents (Figure S2). These results might also indicate a stabilizing effect of the aqueous 20\% [CH][Glu] on protein structural integrity and therefore be another explanation for the good performance of the $20 \%[\mathrm{CH}][\mathrm{Glu}]$ as solvent for the reaction system. 

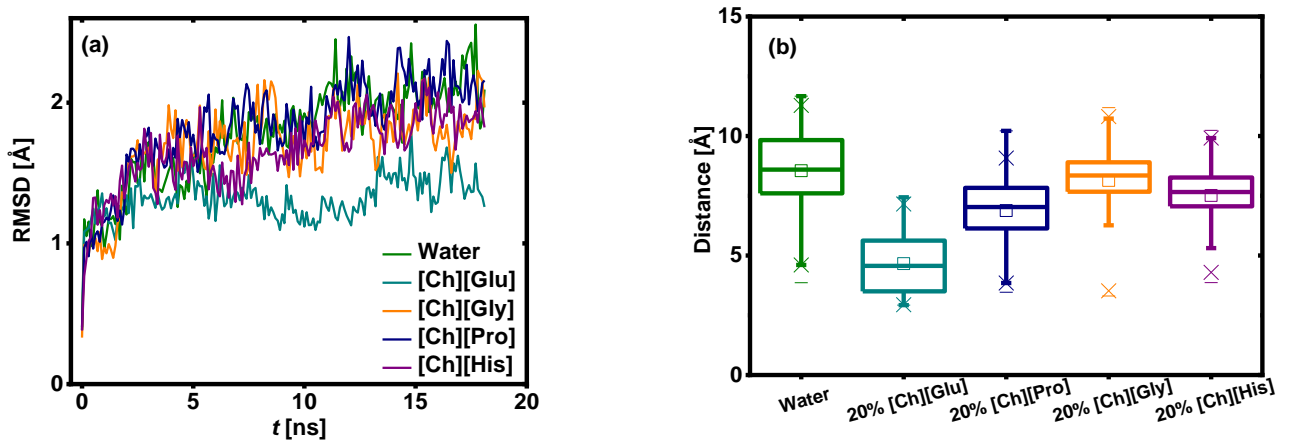

Figure 7. (a) RMSD time course during the molecular dynamics simulations using $\mathrm{H}_{2} \mathrm{O}$ (black line), $20 \%$ [Ch][Gly] (blue line), $20 \%[\mathrm{Ch}][\mathrm{Glu}]$ (red line), 20\% [Ch][His] (green line) and 20\% [Ch][Pro] (pink line) in water as solvents. (b) Distance of the Tyr73 OH-group and Phe $285 \mathrm{C} \zeta$ over the MD simulation time.

(a)
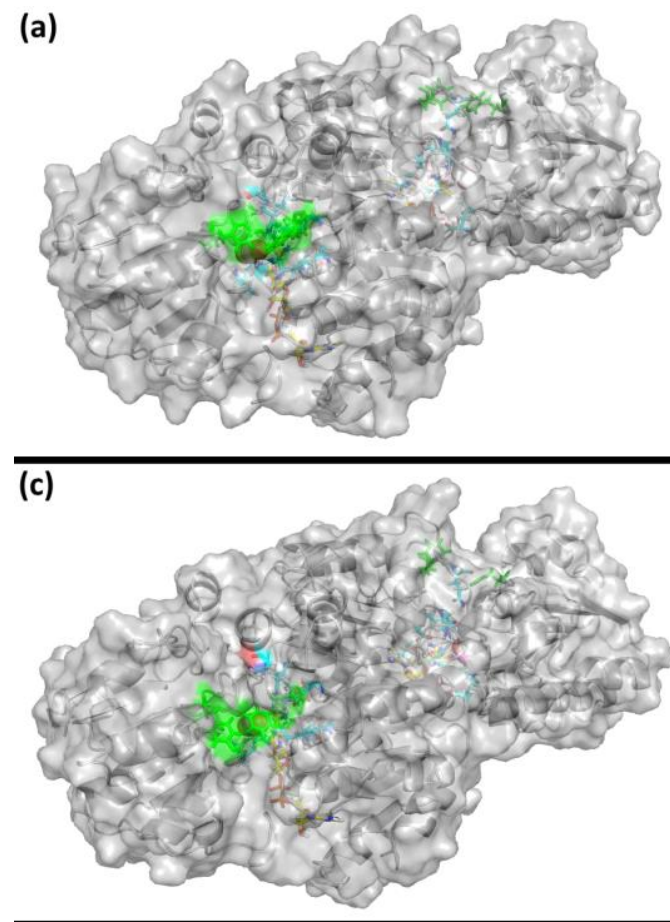

(e)
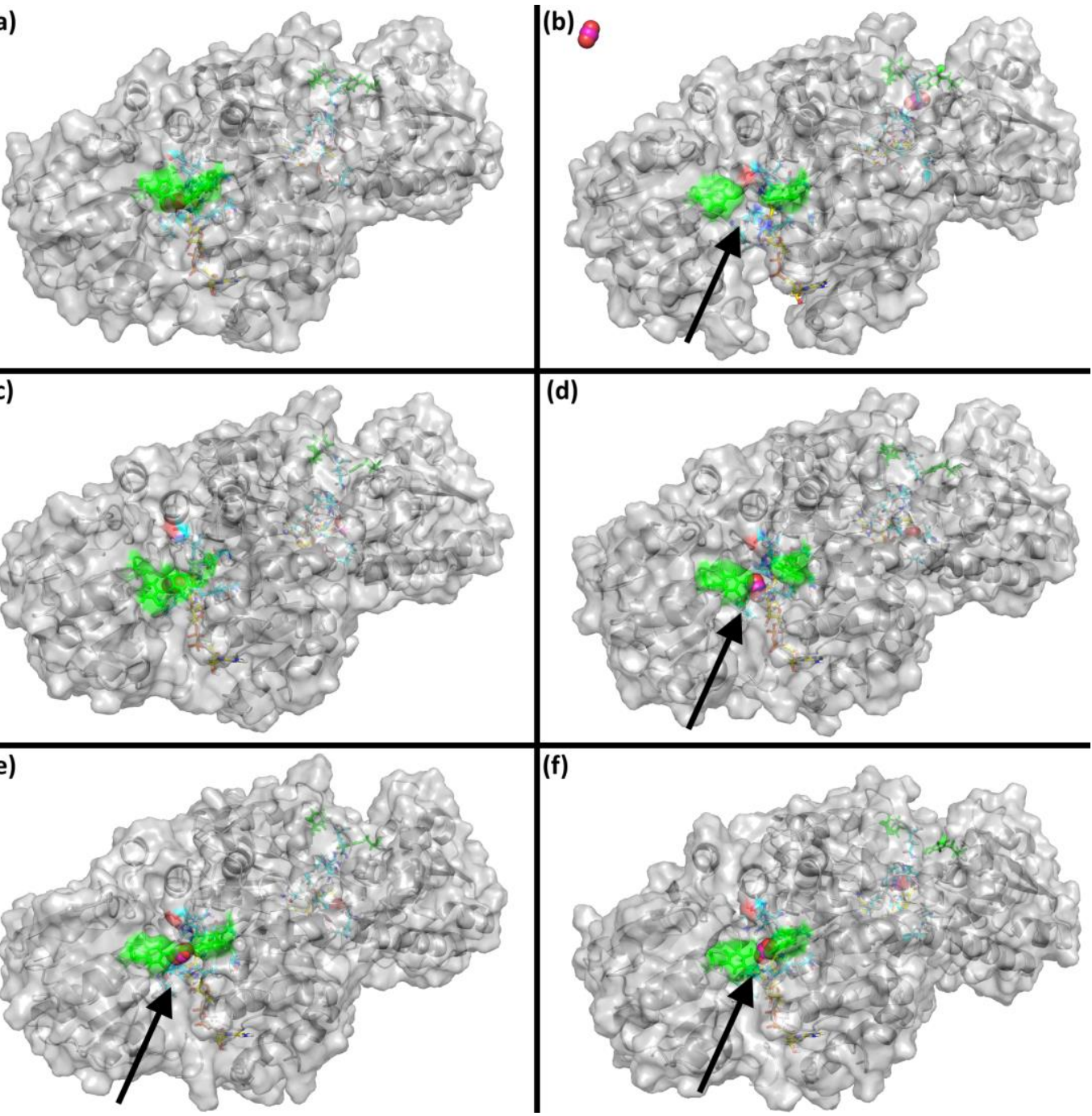

Figure 8. Surface representation of formate dehydrogenase (PDB 5DN9) at the beginning (A) and end (B-F) of MD simulation in different solvent systems: $\mathrm{H}_{2} \mathrm{O}$ (B), 20\% [Ch][Glu] (C), 20\% [Ch][Gly] (D), 20\% [Ch][His] (E), 20\% $[\mathrm{Ch}][\mathrm{Pro}](\mathrm{F})$. For clarity the bulk solvent is not shown. The NADH cofactor is shown as yellow sticks, the catalytically important Arg is shown as cyan sticks, Tyr 73 and Phe 285 are highlighted as greens ticks and green surface, $\mathrm{CO}_{2}$ is shown as cyan spheres. The solvent accessible active sites are highlighted by a black arrow. 
Closer inspection of the MD simulations revealed that in all solvent systems (except 20\% [CH][Glu]) the active site, which binds the $\mathrm{CO}_{2}$ molecule, quickly became solvent accessible (Figure 8, Movies S1-5). This was especially pronounced in the simulation with water as solvent where one of the $\mathrm{CO}_{2}$ molecules has left the active site after 12.5 ns (Figure 8b, Movie S1). As a measure of this surface opening, the distance of the amino acid side chain OH-group of Tyr73 and the $\mathrm{C} \zeta$ of the side-chain of Phe285 was recorded over the simulation time. The $20 \%$ $[\mathrm{CH}][\mathrm{Glu}]$ exhibited significantly different behaviour compared to the other solvent systems and had a mean distance of $4.7 \AA$ while that of the other solvent systems ranged from $6.9-8.5 \AA$ (Figure 7b). Furthermore, detailed analysis of distance between residues and ligands involved in formation of the enzyme transition state (TS, Figure 9A), as reported by Castillo, et al. ${ }^{48}$, revealed clearly that formation of the TS would be favoured far more in the $20 \%[\mathrm{CH}][\mathrm{Glu}]$ system than in all the other systems (Table S4). This effect was also reflected in the root mean square fluctuation (RMSF) values of the residues involved in positioning the $\mathrm{CO}_{2}$ molecule inside the active site (Figure 9B). The amino acid side chains of Asn119, Arg258 and His311 in particular showed a significantly lower fluctuation over the MD simulation time in $20 \%[\mathrm{CH}][\mathrm{Glu}]$ compared to the other solvent systems. As explanation for the high yield of methanol in $20 \%[\mathrm{CH}][\mathrm{Glu}]$ we hypothesize that the increased rigidity of the FDH on the one hand also increases protein stability itself and on the other hand leads to an increased residence time of $\mathrm{CO}_{2}$ in the active site in a more TS-like conformation than in the other studied solvent systems. This prolonged TS-like residence time of $\mathrm{CO}_{2}$ in the active site increases the probability of a productive positioning of the reactants for the formation of formic acid, which thus could result in a shift of the reaction equilibrium towards the less favoured reduction of $\mathrm{CO}_{2}$ to formic acid.
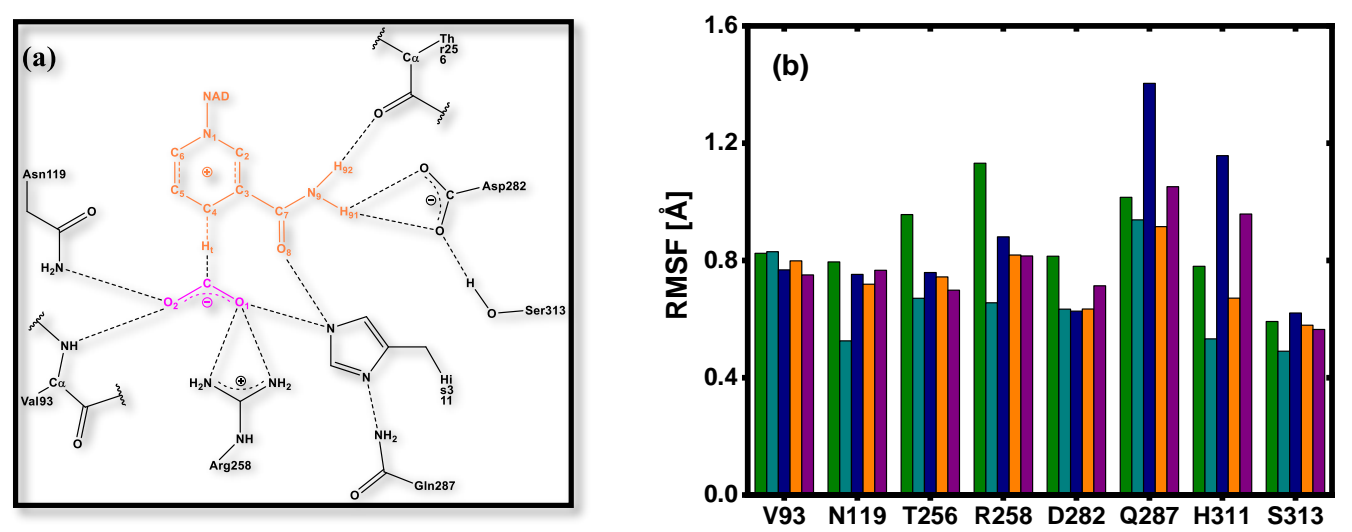

Figure 9. (A) Transition state of the FDH catalyzed reaction as proposed by Castillo et al. The NADH cofactor is highlighted in orange and the substrate $\mathrm{CO}_{2}$ in pink. (B) RMSF values for the amino acid residues involved in substrate and co-factor binding as well as TS formation over MD simulation time for the different solvent systems: $\mathrm{H}_{2} \mathrm{O}$ (olive bars), 20\% [CH][Glu] (Cyan bars), 20\% [CH][Pro] (Blue bars), 20\% [CH][Gly] (Orange bars), 20\% [CH][Pro] (Purple bars).

For further validation of the MD simulation, isothermal titration calorimetry (ITC) was carried out to elucidate the interaction of $\mathrm{FDH}$ with $\mathrm{CO}_{2}$ in the different solvents (i.e. water and $20 \%[\mathrm{CH}][\mathrm{Glu}]$ ). Adsorption heat due to interaction between $\mathrm{FDH}$ with $\mathrm{CO}_{2}$ in water and $[\mathrm{CH}][\mathrm{Glu}]$ was fitted by Nano-Analyze software (TA Instruments) using an independent model to obtain the Gibbs free energy $(\Delta \mathrm{G})$. As shown in Table S1, the $\Delta \mathrm{G}$ value of $\mathrm{CO}_{2}$ interactions with $\mathrm{FDH}$ in water was $-17.12 \mathrm{~kJ} \mathrm{~mol}^{-1}$, which is higher than that of $\mathrm{CO}_{2}$ and FDH interaction in the presence of $[\mathrm{CH}][\mathrm{Glu}]\left(-18.75 \mathrm{~kJ} \mathrm{~mol}^{-1}\right)$. This indicates the binding of $\mathrm{CO}_{2}$ due to lower enzyme flexibility in $20 \%[\mathrm{CH}][\mathrm{Glu}]$. 
A straightforward enzyme loading approach inspired by membrane fouling mechanisms provided a novel platform for conducting a sequential enzyme reaction in the presence of ILs. The biocatalytic system had a promising capacity for enzyme loading and showed high stability after several experimental cycles. Previous studies have shown that the first reaction of the sequence, $\mathrm{CO}_{2} \rightarrow$ formic acid, plays a decisive role in conversion of $\mathrm{CO}_{2}$ to methanol and represents the "bottleneck" that determines the progress of the whole reaction. A strategy to enhance the conversion of this reaction step was attempted by increasing the concentration of $\mathrm{CO}_{2}$ in the reaction system through adding ionic liquids as a co-solvent. The system that offered the best conversion results was an aqueous mixture $20 \%[\mathrm{CH}][\mathrm{Glu}]$ in which $\mathrm{CO}_{2}$ concentration was around 15 times higher than in Tris- $\mathrm{HCl}$ buffer as the control..

Though $\mathrm{CO}_{2}$ concentration achieved was similar in the other ionic liquids selected, the reaction yield significantly increased only when $[\mathrm{CH}][\mathrm{Glu}]$ was used. The reason for this difference was further investigated. We found that $\mathrm{pH}$ might play a significant role in the reaction, because slightly acidic $\mathrm{pH}$ seems to be favour the conversion. The most convincing explanation, however, was provided by molecular simulation dynamics. While $\mathrm{CO}_{2}$ easily diffuses out of the active site in the other ILs tested, and especially in water, the conformation of FDH in the presence of $[\mathrm{CH}][\mathrm{Glu}]$ is such that $\mathrm{CO}_{2}$ stays for a longer time in the vicinity of the active site of the enzyme. Such longer retention times may therefore result in higher conversion of $\mathrm{CO}_{2}$.

Further systematic research on this topic must provide more specific information about the mechanisms and specific functional groups of ionic liquids, which are responsible for the kinds of conformational enzyme changes that can support higher conversions.

\section{Methods}

Materials. Glycine (Gly), L-proline (Pro), L-histidine (His), L-glutamic acid (Glu), Choline hydroxide (aqueous solution $46 \mathrm{wt} \%$ ), were purchased from Sigma Aldrich (St. Louis, MO, USA). Methanol and acetonitrile were analytical grade and used without any further purification. Double-distilled water was used in all experiments. Formate dehydrogenase (EC 1.2.1.2, homo-dimer, $76 \mathrm{kDa}$ ) from Candida boidinii (FDH), formaldehyde dehydrogenase (EC 1.2.1.46, homo-dimer, $150 \mathrm{kDa}$ ) from Pseudomonas sp. (FaldDH), alcohol dehydrogenase (EC 1.1.1.1, homo-tetramer, $141 \mathrm{kDa}$ ) from Saccharomyces cerevisiae (ADH), and glucose dehydrogenase (EC 1.1.1.118, homo-hexamer, $300 \mathrm{kDa}$ ) from Pseudomonas sp. (GDH) were purchased from Sigma-Aldrich (St. Louis, MO, USA). These commercial powders or liquids are not pure enzymes and the protein content was determined by Bradford protein assay. $\beta$-Nicotinamide adenine dinucleotide reduced form (NADH, >97 wt $\%$ ), $\beta$ nicotinamide adenine dinucleotide hydrate $\left(\mathrm{NAD}^{+}\right)$, Trizma base, hydrochloric acid $(37 \%)$ D-glucose, and methanol $(\geqslant 99.9 \%)$ were purchased from Sigma Aldrich (St. Louis, MO, USA). All the enzyme and substrate solutions were prepared using $0.1 \mathrm{M}$ Tris- $\mathrm{HCl}$ buffer $(\mathrm{pH}=7.0)$ unless otherwise stated. $\mathrm{CO}_{2}$ gas $(>99.5 \%)$ in a cylinder was purchased from AGA A/S (Denmark). Commercial UF membranes (PLGC, Millipore) used in this work have a regenerated cellulose skin layer on a polypropylene support, and their molecular weight cut-off is 10 $\mathrm{kDa}$. solution (about $4 \mathrm{M}$ ) was added dropwise under cooling to an amino acid aqueous solution or suspension (0.06 mol) to obtain a slight excess (about $10 \mathrm{~mol} \%$ ) of amino acid. The mixture was stirred at about $3{ }^{\circ} \mathrm{C}$ overnight in the 

was then added under vigorous stirring to precipitate the excess of amino acid. The mixture was left stirring overnight and the excess of amino acid was then filtered off. The filtrate was evaporated to remove solvents at 50 ${ }^{\circ} \mathrm{C}$. The product was dried under vacuum for $72 \mathrm{~h}$ at $60{ }^{\circ} \mathrm{C}$.

Experimental set-up and procedure. The dead-end filtrations and enzymatic reaction were performed in a stirred cell (Amicon 8050, Millipore, USA) and descriptions of equipment and procedure can be found in previous work. ${ }^{8}$ The PLGC membranes (10 kDa) were placed on the membrane holder in 'sandwich' mode (with their own support layer facing the feed and an extra polypropylene support beneath the skin layer). The membrane was first soaked in a $5 \% \mathrm{NaCl}$ solution for $30 \mathrm{~min}$ and then filtered with deionized water for another $30 \mathrm{~min}$ at 1 bar (procedures according to the manufacturers' instructions). Next, the water permeability of the membranes was measured at 2 bar with buffer for $30 \mathrm{~min}$. Then each enzyme solution $(30 \mathrm{~mL})$ was poured into the cell with a $10 \mathrm{kDa}$ membrane for enzyme immobilization. The prepared solution was bubbled with $\mathrm{CO}_{2}$ through a syringe needle $(0.6 \mathrm{~mm} \times 25$ $\mathrm{mm}$ ) before entering the reactor. The flow rate of gas (measured by the speed of bubble emission) was controlled in the same manner in all the experiments by controlling the pressure valve.

Solubility experimental apparatus and procedure. The gas solubility experimental apparatus and procedure are similar to the work of Shang et al. In the experiment $\mathrm{CO}_{2}$ of ambient pressure was bubbled at a flow rate of about $60 \mathrm{~mL} \mathrm{~min}-1$ through about $4.0 \mathrm{~g}$ of the IL in a glass tube with an inner diameter of $12 \mathrm{~mm}$. The glass tube was partly immersed in a water bath of desired temperature. The weight of the IL solution was determined at regular intervals by an electronic balance (OHAUS Corp. AR2140, USA) with a resolution of $0.0001 \mathrm{~g}$.

Enzyme immobilization. Three enzymes of $100 \mathrm{~mL}$ liquid FDH, $1.0 \mathrm{mg}$ solid FaldDH, and $1.5 \mathrm{mg}$ solid ADH were immobilized in the $10 \mathrm{kDa}$ regenerated cellulose membrane. Enzyme immobilization was carried out at a pressure of 2 bar, and permeate was collected in precision cylinders for analysis. The cylinders were replaced manually for every $4 \mathrm{~mL}$. At the end of filtration, the 'fouled' membrane was washed with $10 \mathrm{~mL}$ of buffer at a pressure of 2 bar, and then rinsed 3 times with buffer without pressure. The amount of immobilized enzyme (loading) was calculated from the mass balance equation, and the immobilization efficiency was expressed as enzyme loading efficiency (loading efficiency $=\frac{m_{i}}{m_{t}}$ ) where $\mathrm{m}_{\mathrm{i}}$ and $\mathrm{m}_{\mathrm{t}}$ are amount of immobilized and total enzyme, respectively.

Enzymatic reaction with immobilized enzymes. $\mathrm{NADH}$ solution $(5 \mathrm{mM})$ was prepared with $0.1 \mathrm{M}$ Tris- $\mathrm{HCl}$ buffer and ILs which had been pre-bubbled with $\mathrm{CO}_{2}$ for $30 \mathrm{~min} .4 \mathrm{~mL}$ NADH solution with saturated $\mathrm{CO}_{2}$ was added to the stirred cell equipped with $10 \mathrm{kDa}$ regenerated cellulose membrane. The applied pressure was controlled manually to ensure that $4 \mathrm{~mL}$ permeate was obtained in $30 \mathrm{~min}$. For the enzyme reuse experiment, when $4 \mathrm{~mL}$ of permeate had been obtained, the filtration was paused and another $4 \mathrm{~mL}$ of fresh NADH solution with saturated $\mathrm{CO}_{2}$ was added for the next cycle (each cycle lasted about $30 \mathrm{~min}$ ).

330 Enzymatic reaction with NADH regeneration. $2 \mathrm{mg}$ of additional glucose dehydrogenase (GDH) for NADH regeneration was immobilized together with the other three enzymes (i.e. FDH, FaldDH, ADH) in the $10 \mathrm{kDa}$ regenerated cellulose membrane. Immobilization procedure was the same as given above. The $4 \mathrm{ml} \mathrm{NADH}$ solution with saturated $\mathrm{CO}_{2}$ containing $5 \mathrm{mM}$ NADH and $50 \mathrm{mM}$ D-Glucose as substrate for glucose dehydrogenase was run through the membrane. The obtained permeate was recycled as feed solution in the next reaction cycle and this operation was repeated for six times.

336 Analytical methods. The concentration of enzymes was measured as protein concentration using the Bradford 

used for methanol concentration. The carrier gas was $\mathrm{N}_{2}$ with a flow rate of $0.4 \mathrm{~mL} \mathrm{~min}^{-1}$. The injector temperature was $150{ }^{\circ} \mathrm{C}$ and the injection volume was $1 \mathrm{~mL}$. Methanol GC chromatograms were calibrated with 0.01-1 mM methanol solution in $0.1 \mathrm{M} \mathrm{pH}$ 7.0 Tris- $\mathrm{HCl}$ buffer. Scanning electron microscopy (SEM) was performed in an FEI Helios EBS3 dual beam electron microscope. The skin and support samples were prepared by cutting a small square of the membrane, which was then attached to an aluminium stub by means of double sided sticky carbon tape. The edges of the sample were mounted on the aluminium stub by means of copper tape. After freezing the membrane sample by plunging in liquid nitrogen, cross sections of the membrane skin and the support were cut from the with a pair of scissors. The cross sections were mounted on a slotted specimen stub and fixed with copper tape. All samples were coated with Pt for $2 \mathrm{~s}$ at $80 \mathrm{~mA}$ in a Cressington 208HR Sputter Coater, which gave an approximate thickness of $4 \mathrm{~nm}$. The micrographs were obtained with an Everhart Thornley detector at low magnifications and with a Thru-the-Lens detector at high magnifications, in high vacuum at $5 \mathrm{keV}$ acceleration voltage and $43 \mathrm{pA}$ current. ${ }^{1} \mathrm{H}$ NMR measurements. Spectra were recorded at $298 \mathrm{~K}$ on a Varian XL-600 spectrometer operating at $600 \mathrm{MHz}$. Solutions were prepared by dissolving 20-30 mg of IL in $0.7 \mathrm{~mL}$ of $\mathrm{D}_{2} \mathrm{O}$.

Isothermal titration calorimetry. The titration experiments were performed using a Nano ITC low volume titration calorimeter (TA instruments, New Castle, DE, USA). Titrations were performed at $25^{\circ} \mathrm{C}$ and consisted of enzyme $(\mathrm{FDH})$ and $4.0 \mu \mathrm{L}$ injections of ligand $\left(\mathrm{NaHCO}_{3}\right.$, sodium formate, $\mathrm{NADH}$, or $\left.\mathrm{NAD}^{+}\right)$at 300 -second intervals. All solutions were filtered, degassed to avoid bubble formation, and equilibrated to the corresponding temperature before each experiment. The syringe was inserted into the reaction cell, stirring ( $250 \mathrm{rpm})$ was initiated, and the instrument was equilibrated at $25{ }^{\circ} \mathrm{C}$ until the base line was flat and stable. The titration data were analyzed with Nano Analyze software (TA Instruments) using an independent model to obtain the curve fitting and thermodynamic binding data. Enthalpy of binding was determined for three titrations of each experiment and average values were compared. The intrinsic molar enthalpy change $(\Delta \mathrm{H})$, the binding stoichiometry $(\mathrm{n})$ and binding constant $(\mathrm{K})$ for the binding process were obtained from the best fit of the calorimetric data. Gibbs free energy of binding and $\mathrm{K}_{\mathrm{d}}$ were calculated from binding affinity measurements, using $\Delta \mathrm{G}=-\mathrm{R}(\mathrm{T}) \ln \left(1 / \mathrm{K}_{\mathrm{d}}\right)$, where $\mathrm{R}$ is the universal gas constant and $\mathrm{T}$ is temperature in Kelvin. Entropy of binding was then estimated with $\Delta \mathrm{S}=(\Delta \mathrm{H}-\Delta \mathrm{G}) / \mathrm{T}$, where $\Delta \mathrm{H}$ was the average enthalpy of binding.

Molecular dynamic simulations. Molecular dynamics (MD) simulations were carried out to study the effect of the employed IL water mixtures on FDH. Therefore the structure of FDH from Candida biodinii (pdb code 5DN9) in complex with $\mathrm{NAD}^{+}$and azide was downloaded from the PDB database. In preparation for the MD simulations the azide was replaced with a $\mathrm{CO}_{2}$ molecule in both monomers of the enzyme using the replace function of YASARA 16.9.23 (YASARA Biosciences GmbH, Vienna, Austria). ${ }^{50}$ Next, the program was used to clean the structure and optimize the hydrogen bonding network. To run the simulation in a mixed solvent system, a cubic simulation cell extending $10 \AA$ around all atoms was created and the AMBER15IPQ force field was chosen. ${ }^{51} \mathrm{~A}$ cell neutralization and $\mathrm{pK}_{\mathrm{a}}$ prediction experiment at $\mathrm{pH} 6.85$ was carried out to neutralize the simulation cell and assign correct protonation states of the amino acid side-chains. For creation of the mixed solvent system, all water molecules were deleted from the soup and the solvent density was estimated using weighted densities of the pure compounds as found in the literature. ${ }^{52}$ The specific IL molecules were created using the Build function of YASARA to fill the simulation cell with an aqueous ionic liquid. In the next step the cell was filled with the created molecule using the respective densities specified in Table S3. The rest of the cell was filled with water molecules by temporarily removing the IL molecules, filling the cell with water using the specified density (Table S3), and adding the removed IL molecules back again. To remove all bumps between solvent molecules, the protein was fixed and an energy minimization experiment was carried out. Then all atoms were freed again and the 
the YASARA macro md_run with the pressure control mode "Manometer", pH 6.85 and $298 \mathrm{~K}$ over a time of 18.1 ns. The resulting simulation snapshots were analysed using the YASARA macros md_analyze and md_analyzeres. For visualization in PyMOL (The PyMOL molecular Graphics System, Version 1.1 Schrodinger, Cambridge, MA, USA), the simulation file was converted to pdb using the YASARA macro md_convert. The movies were prepared using OBS Studio (https://obsproject.com)

\section{References}

1. Lim XZ. How to Make the Most of Carbon Dioxide. Nature 526, 628-630 (2015).

2. A1-Saleh YM, Vidican G, Natarajan L, Theeyattuparampil VV. Carbon capture, utilisation and storage scenarios for the Gulf Cooperation Council region: A Delphi-based foresight study. Futures 44, 105-115 (2012).

3. $\mathrm{Xu} \mathrm{XD}$, Moulijn JA. Mitigation of $\mathrm{C} 02$ by chemical conversion: Plausible chemical reactions and promising products. Energ Fuel 10, 305-325 (1996).

4. Hou WB, Hung WH, Pavaskar P, Goeppert A, Aykol M, Cronin SB. Photocatalytic Conversion of $\mathrm{C} 02$ to Hydrocarbon Fuels via PlasmonEnhanced Absorption and Metallic Interband Transitions. Acs Catal 1, 929-936 (2011).

5. Li H, et al. Integrated Electromicrobial Conversion of $\mathrm{CO} 2$ to Higher Alcohols. Science 335, 1596-1596 (2012).

6. Shi JF, et al. Enzymatic conversion of carbon dioxide. Chem Soc Rev 44, 5981-6000 (2015).

7. Obert R, Dave BC. Enzymatic conversion of carbon dioxide to methanol: Enhanced methanol production in silica sol-gel matrices. $J$ Am Chem Soc 121, 12192-12193 (1999).

8. Luo JQ, Meyer AS, Mateiu RV, Pinelo M. Cascade catalysis in membranes with enzyme immobilization for multi-enzymatic conversion of C02 to methanol. New Biotechnol 32, 319-327 (2015).

9. U1rich RUSCHING UM, Peter WILLNOW, Thomas HÖPNER. C02 Reduction to Formate by NADH Catalysed by Formate Dehydrogenase from Pseudomonas 
10. Cui GK, Wang JJ, Zhang SJ. Active chemisorption sites in functionalized ionic liquids for carbon capture. Chem Soc Rev 45, 4307-4339 (2016).

11. Bates ED, Mayton RD, Ntai I, Davis JH. C02 capture by a taskspecific ionic liquid. J Am Chem Soc 124, 926-927 (2002).

12. Gurkan BE, et al. Equimolar C02 Absorption by Anion-Functionalized Ionic Liquids. J Am Chem Soc 132, 2116-+ (2010).

13. Rosen BA, Zhu W, Kaul G, Salehi-Khojin A, Masel RI. Water Enhancement of C02 Conversion on Silver in 1-Ethy1-3Methylimidazolium Tetrafluoroborate. J Electrochem Soc 160, H138H141 (2013).

14. Whipple DT, Kenis PJA. Prospects of C02 Utilization via Direct Heterogeneous Electrochemical Reduction. J Phys Chem Lett 1, 34513458 (2010).

15. Hussain W, Pollard DJ, Truppo M, Lye GJ. Enzymatic ketone reductions with co-factor recycling: Improved reactions with ionic liquid $\mathrm{co}^{-}$ solvents. J Mol Catal B-Enzym 55, 19-29 (2008).

16. Datta S, et al. Ionic liquid tolerant hyperthermophilic cellulases for biomass pretreatment and hydrolysis. Green Chem 12, 338-345 (2010).

17. Eckstein M, Villela M, Liese A, Krag1 U. Use of an ionic liquid in a two-phase system to improve an alcohol dehydrogenase catalysed reduction. Chem Commun, 1084-1085 (2004).

18. Lau RM, van Rantwijk F, Seddon KR, Sheldon RA. Lipase-catalyzed reactions in ionic liquids. Org Lett 2, 4189-4191 (2000).

19. Weaver KD, Kim HJ, Sun JZ, MacFarlane DR, Elliott GD. Cyto-toxicity and biocompatibility of a family of choline phosphate ionic liquids designed for pharmaceutical applications. Green Chem 12, 507-513 (2010).

20. Fujita K MD, Forsyth M. Protein solubilising and stabilising ionic 
21. Fujita K FM, MacFarlane DR, Reid RW, Elliott GD. Unexpected improvement in stability and utility of cytochrome $\mathrm{c}$ by solution in biocompatible ionic liquids. Biotechnol Bioeng 94, 1209-1213 (2006).

470

22. Silva FAE, et al. Sustainable design for environment-friendly mono and dicationic cholinium-based ionic liquids. Ecotox Environ Safe 108, 302-310 (2014).

23. Petkovic M, et al. Novel biocompatible cholinium-based ionic liquids-toxicity and biodegradability. Green Chem 12, 643-649 (2010).

24. Luo JQ, et al. Directing filtration to optimize enzyme immobilization in reactive membranes. $J$ Membrane Sci 459, 1-11 (2014).

25. Wang XL, et al. Bioinspired Approach to Multienzyme Cascade System Construction for Efficient Carbon Dioxide Reduction. Acs Catal 4, 962-972 (2014).

26. Marpani F, Sarossy Z, Pinelo M, Meyer AS. Kinetics based reaction optimization of enzyme catalyzed reduction of formaldehyde to methanol with synchronous cofactor regeneration. Biotechnol Bioeng 114, 2762-2770 (2017).

27. Affandy A, Keshavarz-Moore E, Versteeg HK. Application of filtration blocking models to describe fouling and transmission of large plasmids DNA in sterile filtration. J Membrane Sci 437, 150-159 (2013).

28. Palacio L, Ho CC, Zydney AL. Application of a pore-blockage - Cakefiltration model to protein fouling during microfiltration. Biotechnol Bioeng 79, 260-270 (2002).

29. Li XY, et al. Absorption of CO(2) by ionic liquid/polyethylene glycol mixture and the thermodynamic parameters. Green Chem 10, 879884 (2008).

30. Jianmin Zhang SZ, Kun Dong, Yanqiang Zhang, Youqing Shen, Xingmei Lv. Supported Absorption of $\mathrm{CO}_{2}$ by TetrabutylphosphoniumAmino Acid Ionic Liquids. Chem-Eur J 12, 4021=4026 (2006). 
31. Dean JA. Lange's Handbook of Chemistry.

509

32. Shengjuan Yuan YC, Xiaoyan Ji, Zhuhong Yang, Xiaohua Lu Experimental study of C02 absorption in aqueous cholinium-based ionic liquids. Fluid Phase Equilibr 445, 14-24 (2017).

33. Wang YZ, Li MF, Zhao ZP, Liu WF. Effect of carbonic anhydrase on enzymatic conversion of $\mathrm{CO} 2$ to formic acid and optimization of reaction conditions. J Mol Catal B-Enzym 116, 89-94 (2015).

34. Yuki Kohno H0. Ionic liquid/water mixtures: from hostility to conciliation. Chem Commun 48, 7119-7130 (2012).

35. Hermann Weingärtner CC, Christian Herrmannc How ionic liquids can help to stabilize native proteins. Phys Chem Chem Phys 14, 415-426 (2012).

36. Marc L. Pusey MSP, Megan B. Turner, and Robin D. Rogers. Protein crystallization using room temperature ionic liquids Crystal Growth \& Design 7, 787-793 (2007).

37. Natalie Debeljuh CJB, Luke Hendersonb, Nolene Byrne. Structure inducing ionic liquids-enhancement of alpha helicity in the Abeta $(1-40)$ peptide from Alzheimer's disease. Chem Commun 47, 63716373 (2011).

38. Megan B. Turner SKS, Jonathan G. Huddleston, John D. Holbreya, Robin D. Rogers. Ionic liquid salt-induced inactivation and unfolding of cellulase from Trichoderma reesei. Green Chem 5, 443-447 (2003).

39. Seddon DSHAJSASR. Enzyme aggregation in ionic liquids studied by dynamic light scattering and small angle neutron scattering. Green Chem 9, 859-867 (2007).

40. Liu WF, Hou YH, Hou BX, Zhao ZP. Enzyme-catalyzed Sequential Reduction of Carbon Dioxide to Formaldehyde. Chinese J Chem Eng 22, 1328-1332 (2014).

41. Sarcar S, Jain TK, Maitra A. Activity and Stability of Yeast Alcohol-Dehydrogenase (Yadh) Entrapped in Aerosol 0t Reverse Micelles. Biotechnol Bioeng 39, 474-478 (1992). 
549

550

551

552

553

554

555

556

557

558

559

560

561

562

563

564

565

566

567

568

569

570

571

572

573

574

575

576

577

578

579

580

581

582

583

584

585

586

587

588

589

590

591

42. Baskaya FS, Zhao XY, Flickinger MC, Wang P. Thermodynamic Feasibility of Enzymatic Reduction of Carbon Dioxide to Methanol. Appl Biochem Biotech 162, 391-398 (2010).

43. Qianyun Sun YJ, Zhongyi Jiang, Lei Zhang, Xiaohui Sun, Jian Li. Green and Efficient Conversion of $\mathrm{C0} 2$ to Methanol by Biomimetic Coimmobilization of Three Dehydrogenases in Protamine-Templated Titania. Ind Eng Chem Res 48, 4210-4215 (2009).

44. Bilal E1-Zahab DD, Ping wang. Particle-tethered NADH for production of methanol from $\mathrm{C} 02$ catalyzed by coimmobilized enzymes. Biotechnol Bioeng 99, 508-514 (2007).

45. Rémi Cazelles JD, François Fajula, Ovidiu Ersen, Simona Moldovanb, Anne Galarneau. Reduction of $\mathrm{C0} 2$ to methanol by a polyenzymatic system encapsulated in phospholipids-silica nanocapsules. NeW J Chem 37, 3721-3730 (2013).

46. Xiaoyuan Ji ZS, Ping Wang, Guanghui Ma, Songping Zhang. Tethering of Nicotinamide Adenine Dinucleotide Inside Hollow Nanofibers for HighYield Synthesis of Methanol from Carbon Dioxide Catalyzed by Coencapsulated Multienzymes. Acs Nano 9, 4600-4610 (2015).

47. Obón JM MA, Iborra JL. Retention and regeneration of native NAD (H) in noncharged ultrafiltration membrane reactors: application to Llactate and gluconate production. Biotechnol Bioeng 57, 510-517 (1998).

48. R. Castillo M0, S. Martí, V. Moliner. A Theoretical Study of the Catalytic Mechanism of Formate Dehydrogenase. J Phys Chem B 32, 10012-10022 (2008).

49. De Santis S, et al. Cholinium-amino acid based ionic liquids: a new method of synthesis and physico-chemical characterization. Phys Chem Chem Phys 17, 20687-20698 (2015).

50. Krieger E, Vriend G. YASARA View-molecular graphics for all devicesfrom smartphones to workstations. Bioinformatics 30, 2981-2982 (2014).

51. Debiec KT, Cerutti DS, Baker LR, Gronenborn AM, Case DA, Chong LT. Further along the Road Less Traveled: AMBER ff15ipq, an Original 
598

599
Protein Force Field Built on a Self-Consistent Physical Model. J Chem Theory Comput 12, 3926-3947 (2016).

52. de1 01mo L, Lage-Estebanez I, Lopez R, de la Vega JMG. Understanding the Structure and Properties of Cholinium Amino Acid Based Ionic Liquids. J Phys Chem B 120, 10327-10335 (2016). 